NASA Technical Memorandum 102108

AIAA-89-2725

\title{
5-kW Arcjet Power Electronics
}

R.P. Gruber, R.W. Gott, and T.W. Haag

Lewis Research Center

Cleveland, Ohio

Prepared for the

25th Joint Propulsion Conference

cosponsored by the AIAA, ASME, SAE, and ASEE

Monterey, California, July 10-12, 1989 


\title{
5-KW ARCJET POWER ELECTRONICS
}

\author{
R.P. Gruber, R.W. Gott, and T.W. Haag \\ National Aeronautics and Space Administration \\ Lewis Research Center \\ Cleveland, Ohio 44135
}

\section{SUMMARY}

Future, large Earth orbital spacecraft could benefit from arcjet systems in the 2 to $5 \mathrm{~kW}$ power range for a variety of applications including stationkeeping, orbit adjustments, and logistics. The arcjet power processor represents the system element with the largest mass and most impactive system interfaces. This paper describes the initial design and evaluation of a $5 \mathrm{~kW}$ arcjet power electronics breadboard which as been integrated with a modified $1 \mathrm{~kW}$ design laboratory arcjet.

A single stage, $5 \mathrm{~kW}$ full bridge, pulse width modulated (PWM), power converter was developed which was phase shift regulated. The converter used metal oxide semiconductor field effect transistor (MOSFET) power switches and incorporated current mode control and an integral arcjet pulse ignition circuit. The unoptimized power efficiency was 93.5 and 93.9 percent at $5 \mathrm{~kW}$ and 50 A output at input voltages of 130 and $150 \mathrm{~V}$, respectively. Line and load current regulation at 50 A output was within 1 percent. The converter provided up to $6.6 \mathrm{~kW}$ to the arcjet with simulated ammonia used as a propellant.

\section{INTRODUCTION}

Renewed interest in arcjets has led to the recent development and life tests of both 1 and $30 \mathrm{~kW}$ arcjet systems for application to North-South (N-S) stationkeeping of geosynchronous satellites and prime propulsion, respectively (refs. 1 to 4). Future high power geosynchronous satellites could have significantly increased $\mathrm{N}-\mathrm{S}$ and East-West stationkeeping requirements due to increased mass and/or area to mass ratios (ref. 5). Thrust levels of intermediate power ( 2 to $5 \mathrm{~kW}$ ) arcjets appear advantageous for these satellites. Earth-orbit missions which require drag make up or orbit adjustments might find the performance of a high specific impulse 2 to $5 \mathrm{~kW}$ arcjet systems beneficial.

The power processor represents the most massive arcjet system component (ref. 6). In addition, its interfaces are the most impactive to the spacecraft. Its design is therefore very sensitive to the anticipated power system requirements of future satellites, as well as thruster needs. Some of the power processor requirements imposed by the spacecraft are the input voltage range, input-output electrical isolation, electromagnetic interference (EMI), and high power efficiency, and low mass.

Arcjet systems in the 2 to $5 \mathrm{~kW}$ power range will likely be energized from high voltage $(>28 \mathrm{~V})$ buses, since high bus voltage results in low spacecraft power system mass. In addition, a typical unregulated spacecraft battery bus will require operation around \pm 10 percent of the nominal input voltage. Furthermore, the need to accommodate conventional spacecraft single point power grounding schemes will make input-output isolation necessary to prevent the possibility of destructive currents being initiated by the conductive 
plasma generated during arcjet operation. Spacecraft electromagnetic interference (EMI) requirements are usually very conservative and specify reflected ripple limitations that result in the need for power filters with significant mass. Finally, high power efficiency is necessary to minimize the impact on the spacecraft thermal control system mass, since the power processor temperature must be kept low to achieve maximum reliability.

During steady state operation the arcjet requires fast response constant current regulation, as well as modest current ripple for stable operation (ref. 7). Ignition is accomplished with a high voltage pulse to breakdown the unionized gas. Startup and transfer to steady state operation must be accomplished reliably without causing thruster damage or excessive wear (ref. 8). Therefore, maximum current must be limited during this transition.

For a high power thruster system operating from a high voltage bus, a full bridge pulse width modulated (PWM) power converter with transformer isolation was chosen for development because it has advantages over the parallel converter developed earlier (ref. 7). An integral thruster pulse ignition function using the output current averaging inductor (ref. 8) was incorporated into the bridge converter.

The laboratory $5 \mathrm{~kW}$ radiation cooled arcjet used for this work was an extension of the $1 K$ design detailed in reference 9 . The primary purpose of this thruster was to provide a representative dynamic load to the power electronics. Specific differences from the $1 \mathrm{~kW}$ class laboratory arcjet were modifications to the constrictor, mixing chamber, and nozzle as well as operation at markedly higher temperatures.

This paper describes the preliminary design, fabrication and evaluation of a single power stage $5 \mathrm{~kW}$ PWM full bridge power converter used to start up and control a laboratory arcjet operating on hydrogen nitrogen gas mixtures which simulated hydrazine decomposition products and ammonia. Power circuit waveforms and benchmark regulation, load transient response, ripple, mass and power efficiency are provided for the breadboard power electronics. System startup transient and initial steady state performance data are presented.

\section{NOMENCLATURE}

A Boolean algebra expression for half cycle pulse width modulated signal A

B Boolean algebra expression for half cycle pulse width modulated signal $B$

DC Constrictor diameter, $\mathrm{mm}$

$L_{C}$ Constrictor length, mm

$\phi_{R}$ Boolean algebra expression for bridge reference side $Q_{1}$ turn on signal

\$S Boolean algebra expression for bridge phase shifted side $Q_{3}$ turn on signal 


\section{POWER ELECTRONICS REQUIREMENTS}

Since no specific, detailed spacecraft requirements yet exist for $5 \mathrm{~kW}$ arcjet power electronics, certain assumptions based upon previous experience must be made. For example, a nominal input bus voltage must be chosen. For this initial breadboard, many issues were not addressed either because they are straightforward (e.g., internal $\pm 15 \mathrm{~V}$ signal level power supplies) or because detailed spacecraft or arcje $\bar{t}$ requirements will have a major impact on that part of power supply (e.g., input EMI filter). In the absence of detailed specifications, initial breadboard efforts concentrated on the development of a power circuit capable of high efficiency and low mass. First efforts were directed towards proving $5 \mathrm{~kW}$ power circuit viability, accomplishing thruster integration, and achieving some of the first steps needed for high power efficiency.

\section{Spacecraft Interface}

A dc bus voltage of $140+10 \mathrm{~V}$ was chosen. The nominal input voltage of $140 \mathrm{~V}$ was judged to represent a compromise between a high voltage, low mass power distribution system and the need to be concerned about potential Paschen breakdown. Critical pressures might occur from the bleeding off of entrapped gas or from outgasing as spacecraft surface temperatures rise. At this writing, Space Station Freedom is now providing regulated $120 \mathrm{Vdc}$ power to users. Voltage regulation and other bus parameters are being determined. Input voltage variation of $\pm 10 \mathrm{~V}$ was chosen to demonstrate line regulation capability. Wider variations of input voltage could be accommodated if necessary, but power electronics mass and/or power efficiency would be adversely affected.

High power efficiency is needed to minimize the impact on the spacecraft thermal control system and to maximize propulsion system performance. Concentrated waste heat generated inside a single stage power supply might make smaller multiple paralleled power stages thermally simpler, but multiple stages add circuit complexity. Therefore a single power stage was chosen for this work. This approach establishes a building block of up to $5 \mathrm{~kW}$ should parallel power stages be required later. Multiple phase staggered PWM power stages have been used previously for a $30 \mathrm{~kW}$ arcjet (ref. 3) and a $30 \mathrm{~cm}$ ion thruster (ref. 10). It is judged that the paralleled stage arcjet ignition pulser could be easily implemented by simultaneously switching the primaries of the output averaging inductors/pulse transformers. The conventional spacecraft single point power ground connected to spacecraft structure makes input-output circuit isolation necessary. This prevents the possibility of destructive currents from being initiated by the conductive plasma generated by an arcjet.

Command and telemetry, as well as internal $\pm 15 \mathrm{~V}$ signal level power converters, are straightforward and were therefore not included in this work. It was also judged that an EMI filter could be added later, when requirements are known. Component derating and use of flight qualified parts were not addressed in this initial effort. 


\section{Thruster Interface}

Thruster interface issues, such as compatibility with the negative resistance thruster volt-ampere characteristic and startup requirements, were resolved earlier for the $1 \mathrm{~kW}$ thruster (refs. 7 and 8 ). Thruster arc current ripple was about \pm 15 percent average to peak and any effects of ripple amplitude and frequency have not yet been determined. For this work, arc current ripple and current regulation was arbitrarily chosen to be \pm 2 percent average to peak and $\pm l$ percent at $50 \mathrm{~A}$, respectively. Fast response constant current regulation was required for arc stabilization, just as for the $1 \mathrm{~kW}$ thruster. In addition, active current overshoot limiting at $55 \mathrm{~A}$, and short circuit protection, were incorporated. Provisions to operate at arc currents from 10 to $50 \mathrm{~A}$ were also included.

The constrictor dimensions and the gap setting of the $5 \mathrm{~kW}$ arcjet were larger than for the $1 \mathrm{~kW}$ arcjet, so the pulser was designed to handle more energy and provide a higher voltage. Peak pulser voltage was set at $4.5 \mathrm{kV}$ and the maximum current available at breakdown was adjusted to $12 \mathrm{~A}$. Because the initial breakdown current is a small fraction of the 50 A operating current, and should stay the same for future $5 \mathrm{~kW}$ arcjets, the pulser design will remain straightforward.

\section{POWER ELECTRONICS DESIGN}

\section{Circuit Selection}

Earlier success at $1 \mathrm{~kW}$ with a PWM parallel converter incorporating an output current averaging inductor/pulse startup transformer (ref. 8) led to retention of this basic scheme for the $5 \mathrm{~kW}$ design. However, for this effort, a full bridge PWM converter (fig. l(a)) was chosen over the parallel PWM converter used in the $1 \mathrm{~kW}$ work for two principal reasons. First the higher current levels in high power PWM converters result in substantial energy storage in the transformer leakage inductance during each half cycle. A parallel converter must either dissipate this energy or transfer it to the source or load using special circuits. A bridge converter can handle this high energy each half cycle without the need for special circuits. Secondly, in a full bridge circuit the power switches see only input voltage when off, whereas parallel converter switches operate at twice input voltage. Therefore, the bridge power transistors voltage rating need only be slightly higher than the maximum input voltage. The major disadvantage of a full bridge is that four power switches, with their associated drive circuits, are required instead of two. Power transistors are a highly stressed component and usually the most likely component to fail, so reliability is diminished when more power transistors are needed. However, the potential full bridge disadvantage of two cascaded switches is substantially lessened when power MOSFET's are used. Because, for a given MOSFET die size, ON resistance is proportional to OFF state breakdown voltage. Therefore, for adequately voltage rated switches, the total power switch ON resistance will be nearly the same for either a full bridge (two "ON" MOSFETS in series) or parallel converter (one higher voltage "ON" MOSFET). Another advantage of a bridge converter is that the power transformer is simpler and has less mass than the parallel converter power transformer since only one primary winding is needed. 
Three choices of full bridge drive techniques were considered. The conventional technique of simultaneously turning ON and OFF diagonal pairs of switches was not chosen because leakage inductance energy is not well controlled. When all four transistors are off, the leakage inductance current commutation causes extra power wasting switch transitions in the output rectifiers. A second technique, reported by Goldfarb (ref. 11) appeared to control leakage inductance energy and reduce switching losses by using capacitors across the two switches that turn off reflected load current. However, this concept was judged to be more difficult to implement due to the more complicated logic and extra current sensing than the phase shift control scheme finally chosen. Two high power phase shift controlled PWM full bridge power converters were found in the early literature. The first, in 1965, was reported by Ernsberger (ref. 12). Four vintage, slow, silicon bipolar transistors were operated at $800 \mathrm{~Hz}$ in a single power circuit to provide $2 \mathrm{~kW}$ at 88 percent power efficiency with an input voltage of $100 \pm 10 \mathrm{~V}$. Phase shift was accomplished with a Ramey magnetic amplifier. The design comprised only about 220 components without using integrated circuits. In 1976. Ahrens and Cardwell (ref. 13) described a phase shift controlled PWM converter with which they were able to achieve power efficiencies of 93 percent for a $0.6 \mathrm{~kW}$ single stage, $45 \mathrm{~V}$ output supply, and 96 percent for a $2.4 \mathrm{~kW}$ four stage,

$1100 \mathrm{~V}$ output supply $(0.6 \mathrm{~kW}$ per stage). For both supplies, the input voltage range was 200 to $400 \mathrm{~V}$ and the converters operated at $10 \mathrm{kHz}$ with each converter stage phase staggered to minimize input filter mass. The design was a difficult task because the only fast, high voltage medium current bipolar transistors available in the early 1970's were also fragile. The $2.4 \mathrm{~kW}$ converter had five power stages including one stage used for standby redundancy. Elaborate power transistor drive and protection, stagger phase operation, and the performance and mass requirements led to a very complex power supply comprising an estimated 1000 components.

The low switching losses and high power efficiency achieved for the $0.6 \mathrm{~kW}$ power stage led to the choice of the phase shift regulated full bridge for this $5 \mathrm{~kW}$ work. The power circuit configuration with its simplified voltage waveforms is shown in figure 1 , which was taken from reference 13 . In this circuit, each side of the bridge $\left(Q_{1}, Q_{2}\right)$ or $\left(Q_{3}, Q_{4}\right)$ is driven by a square wave so each power switch is on for one half cycle while the other switch in that side is off. Regulation is achieved by shifting the phase of the $\left(Q_{3}, Q_{4}\right)$ side from $0^{\circ}$ to $-180^{\circ}$ with respect to the reference side $\left(Q_{1}, Q_{2}\right)$. There is no output at $0^{\circ}$ and full output at $-180^{\circ}$. Idealized voltage waveforms for an intermediate output power are shown in figure $1(b)$. Current waveforms are more complex and will be discussed later.

For this work, paralleled power MOSFET's were used as switches instead of bipolar transistors. Power MOSFET's are easier to drive and operate in parallel to reduce ON resistance. MOSFET's are fast and free from second breakdown. In addition, a relatively new control method, current mode control (refs. 14 and 15) was used. Current mode control limits pulse by pulse current so the power switches are protected from overcurrents. Furthermore, initial arcjet startup current overshoot can be controlled to a preset value by this control method. Current mode control is usually used to control output voltage. Instead, for this $5 \mathrm{~kW}$ converter design, average output current was the controlled parameter. Peak output current was used for convenience as the controlled parameter for the I kW power supply design (ref. 6). There is a small but variable difference between peak and average 
output current. Therefore, peak output current control results in less accurate current regulation than the average output current control used for the $5 \mathrm{~kW}$ converter.

\section{Design Details}

The initial control circuits incorporated the control circuit board assembly previously designed and fabricated for a new $2 \mathrm{~kW}$ PWM arcjet power supply. The PWM power switch drive was converted to a phase shifted power switch drive having a reference side square wave drive and a 0 to $-180^{\circ}$ phase shifted side drive and is shown in figure 2. This was done instead of going directly from the current mode comparator signal to the phase shift function in order to save design and fabrication time. The conversion from PWM to phase shift power switch drive was accomplished by developing a logic circuit using a flip flop for the reference phase, and combinational logic circuits to implement:

$$
\phi_{S}=\overline{\phi_{R}} \cdot(A+B)+\phi_{R} \cdot \overline{(A+B)}
$$

For the condition where the PWM output is zero, all drive is removed from the bridge.

The remainder of the functions shown in figure 2 describe the conventional current mode control and pulser control logic used earlier for the $1 \mathrm{~kW}$ supply (ref. 7). For current mode control, the slope compensation function shown in figure 2 is necessary to prevent unconditional instability for PWM duty ratios above 50 percent. Besides saving design time, this control approach allowed the use of a current mode PWM controller integrated circuit which incorporates most of the necessary circuit functions for current mode control. However, for future designs it may be advantageous to go directly from the current mode comparator signal into a phase shift controller, eliminating the intermediate PWM logic with its associated time delay.

The authors found no descriptive power switch or transformer current waveforms in the literature. In addition, there was a need to verify the control and logic circuit designed for the $5 \mathrm{~kW}$ converter. Therefore, a $30 \mathrm{~W}$ model of the converter was fabricated and tested using the scheme shown in figure 2. The bridge was configured as shown in figure 1 (a) except that IRF250 power MOSFETs instead of bipolar transistors were used for $Q_{1}$ through $\mathrm{Q}_{4}$. Synchronized drain-source switch voltages for $Q_{1}$ through $Q_{4}$ and transformer primary and secondary voltages are shown together with switch drain and transformer currents in figure 3 . The phase shifted side current waveforms, $Q_{3}, Q_{4}$, are quite different from the reference side waveforms, $Q_{1}, Q_{2}$. The reference side, $Q_{1}$ or $Q_{2}$ turns on the total current reflected by the load and the transformer magnetizing current. Rectifier diode reverse recovery current is limited by the transformer leakage and parasitic circuit inductances. The reference side turns off only transformer magnetizing and leakage inductance currents. The phase shifted side, $Q_{3}$ or $Q_{4}$, turns on, in the reverse direction, part of the load current, as well as transformer leakage inductance and magnetizing current, but turns off reflected load current and transformer magnetizing current in 
the forward direction. The phase shifted side, $Q_{3}$ or $Q_{4}$ conducts reverse current through the power MOSFET source-drain with the intrinsic anti-parallel diode not conducting. This property may not be widely known because the anti-parallel diodes are conventionally used to conduct reverse currents as the MOSFET's are turned off. So during steady state operation of this type bridge, the power MOSFET intrinsic anti-parallel diodes do not conduct as long as the source drain voltage is below about $0.7 \mathrm{~V}$. For the $30 \mathrm{~W}$ model, source-drain voltage measured about $0.1 \mathrm{~V}$. This is significant because switch drop is well below the $0.7 \mathrm{~V}$ diode forward voltage drop. Therefore, power efficiency need not be reduced by accepting the $0.7 \mathrm{~V}$ diode drop and operation at low input voltage (e.g., $50 \mathrm{~V}$ ) at high power should be practical with a phase controlled full bridge PWM converter using lower voltage, lower ON resistance power MOSFET's. There may be some diode conduction on the order of 1 usec, but drain-source voltage waveforms show that the power MOSFET and not the intrinsic diode quickly conducts virtually all the reverse current.

A detailed circuit description for the $5 \mathrm{~kW}$ power supply, as well as circuit schematic diagrams, are given in the appendix. A photograph of the $5 \mathrm{~kW}$ power electronics breadboard appears in figure 4 . The photograph shows the control electronics and logic circuit boards enclosed in an aluminum chassis shield. The smaller covered aluminum chassis houses the +15 and $24 \mathrm{~V}$ control circuit power supplies which are powered from $115 \mathrm{Vac}$. The output diode heat sink, a drive transformer, main power transformer, current sensing transformer, output averaging inductor/pulse transformer can be seen in larger assembly. Two cooling fans were also included in the power supply.

\section{TESTS}

The $5 \mathrm{~kW}$ power electronics breadboard was tested with a resistive load and with a laboratory thruster load. The laboratory arcjet thruster used for initial $5 \mathrm{~kW}$ testing was identical to a $1 \mathrm{~kW}$ design used in a $1000 \mathrm{hr}$ cycled life test (ref. 9), except that the constrictor diameter in the anode was enlarged to accommodate high gas flow rates. A cut away view of the arcjet is shown in figure 5. The upstream converging conical half angle was $30^{\circ}$ and the downstream diverging half angle was $20^{\circ}$. The original $0.64 \mathrm{~mm}$ diameter by $0.41 \mathrm{~mm}$ long constrictor was increased to $0.89 \mathrm{~mm}$ diameter and $0.89 \mathrm{~mm}$ in length. The cathode used was a $3.18 \mathrm{~mm}$ diameter thoriated tungsten rod, $20 \mathrm{~cm}$ in length. The cathode end of the cathode was ground to a conical tip with a $30^{\circ}$ half angle. The arc gap was set by withdrawing the cathode $0.76 \mathrm{~mm}$ from contact with the anode. A photo of this arcjet in operation on a thrust stand is shown in figure 6 .

\section{Loadbank Tests}

Resistive load tests were performed to obtain typical steady state converter operating waveforms, and to establish benchmark pulser voltage, regulation, load transient response, ripple and power efficiency.

Converter waveforms. - Bridge converter power switch drain to source voltage waveforms for $Q_{2}$ and $Q_{4}$ (circuit location is given in fig. 1) are synchronized with and shown with the transformer primary current in figure 7 for a $5 \mathrm{~kW}$ resistive load. $Q_{1}$ and $Q_{3}$ waveforms are not shown 
since voltage waveforms for each transistor in the reference side of the bridge, $Q_{1}$ and $Q_{2}$ look the same, but are $180^{\circ}$ out of phase. The same is true for $Q_{3}$ and $Q_{4}$. The reference side, $Q_{1}$ or $Q_{2}$ turns on into transformer magnetizing current, the reflected load current, and the reverse recovery current of one output rectifier diode pair. Current rise is limited by the power transformer leakage inductance and a small current limiting inductor. The reference side, $Q_{1}$ or $Q_{2}$ also turns off residual current flowing in the transformer leakage inductance and current limiting inductor, as well as the transformer magnetizing current. This residual current decays slowly for this high power circuit, mainly because the ratio of current limiting inductance and leakage inductances to switch resistance is high. The phase shifted side of the bridge $\left(Q_{3}\right.$ or $\left.Q_{4}\right)$ turns off reflected load current and transformer magnetizing current and is already turned on when load current is switched on by the reference side. Due to ringing at switch transitions, the power switches which are rated for $200 \mathrm{~V}$ see about $170 \mathrm{~V}$ at an input voltage of $150 \mathrm{~V}$ and an output power of $5 \mathrm{~kW}$. The transformer primary current reaches nearly $60 \mathrm{~A}$ peak. The rms transformer primary current value remains close to $50 \mathrm{~A}$ even though the duty ratio is near 2/3. Primary rms current changes little with duty ratio.

Occasionally, at initial turn on into a $5 \mathrm{~kW}$ load, the bridge would startup with a nondestructive, stable current imbalance where the main transformer core would begin to saturate once each cycle. Although the small current limiting inductor reduced the transformer primary applied volt-seconds during the saturating half cycle and would be expected to correct the imbalance, the next half cycle showed a notch on the leading edge of the transformer voltage. This condition only occurred with a resistive load and never happened during thruster integration. This stable imbalance did not occur when a molybdenum-permalloy powder (MPP) power transformer core with a markedly less pronounced saturation characteristic was used with no current limiting inductor. This stable condition was not investigated at this time because further circuit modifications were being planned to improve power efficiency.

Pulser output. - The pulser produces a high voltage pulse every half second until arc current is sensed. This is the same scheme described in references 7 and 8 . The pulser transformer/current averaging inductor primary current is allowed to reach about $120 \mathrm{~A}$ before the primary power MOSFET's are switched off. Since the pulser transformer/current averaging inductor turns ratio is about 10:1, the maximum current available at arcjet ignition is near $12 \mathrm{~A}$. Open circuit pulser voltage reaches $4.6 \mathrm{kV}$ in about $3 \mu \mathrm{s}$ and is shown in figure 8 .

Regulation. - Current regulation data are given in table I for 10 and 50 A reference setpoints with input voltages of 130 and $150 \mathrm{~V}$ at each setpoint. Static current regulation was within 1 percent of the 50 A setpoint once the load resistance was set low enough to pass sufficient current. Accurate static load current regulation was expected since a shunt was used to sense average load current which was fed back to an integral current control loop.

Transient response. - Figure 9 shows load current transient response measured at 50 A output for step load changes from 1 to $2 \Omega$ and from 2 to $1 \Omega$ using a solid state switch. Voltage waveforms resulting from the load 
transients exhibit the effects of parasitic series inductance in the $30 \mathrm{~kW}$ loadbank and its connections. Resultant load current overshoot and undershoot were about 10 percent and of nearly $300 \mu s$ duration.

Ripple. - Load current ripple at an output current of $50 \mathrm{~A}$ can be seen in figure 9. Ripple measured approximately $2 \mathrm{~A}$ peak to peak at $16.7 \mathrm{kHz}$. If desired, ripple could be increased by lowering the operating frequency or by decreasing the averaging inductance. Reflected input current ripple measured about $3 \mathrm{~A}$ peak to peak at $16.7 \mathrm{kHz}$ and the oscilloscope trace appeared to contain no spikes and no significant high frequency components. The $5 \mathrm{~kW}$ power electronics breadboard input filter was a large capacitor and no input filter inductors were used.

Power efficiency. - At $5 \mathrm{~kW}$ power efficiency measured 92.2 percent with $150.6 \mathrm{~V}$ input and 92.0 percent at $130.1 \mathrm{~V}$ input. Current shunts matched to 0.25 percent were used to measure input and output currents. The same digital voltmeter at the same polarity was used to measure input and output shunt and converter voltages. Measurements were made with and without a $100 \mu \mathrm{F}$ low equivalent series resistance capacitor across the output. Power efficiency measured 0.1 percent higher without the capacitor. A large capacitor to reduce ripple for the power efficiency measurement reported for the $1 \mathrm{~kW}$ supply (ref. 7) had the effect of reducing the measured power efficiency by about $11 / 2$ percent from the measurement without the capacitor. However, the current ripple for the $1 \mathrm{~kW}$ power supply was an order of magnitude more percentage than that of the $5 \mathrm{~kW}$ power supply. For the $1 \mathrm{~kW}$ work an $\mathrm{R}-\mathrm{C}$ filter used to filter the current signal from the shunt resulted in sufficiently accurate measurements (within 0.5 percent) without resorting to the use of a large capacitor across the output. For the $5 \mathrm{~kW}$ measurements an RC filter was used across the input shunt to reduce ripple effects. This reduced the measured power efficiency by about 1.5 percent. The power efficiency reported here is estimated to be accurate within +1 percent. It is judged that a power efficiency nearly 95 percent at $5 \mathrm{~kW}$ could be achieved with this type converter. An efficiency increase of 2 percent is available by reducing the switch transistor (four parallel IRF250 MOSFET's for each switch) conduction losses which are about $110 \mathrm{~W}$ in the present design. Transistor conduction losses could be reduced to $20 \mathrm{~W}$ by using hybrid MOSFET switches containing 24 IRF 250 chips. Optimizing the output inductor and power transformer to reduce copper and core losses and decreasing switching losses by eliminating the current limiting inductor and improving the drive circuits could add another 1 or 2 percent to the power efficiency. However, about 0.5 percent power efficiency would be lost by adding inductors to the input filter to meet EMI requirements.

Subsequent to all the tests described in this report, the power circuit was modified and the power MOSFET's were replaced with four power hybrids containing 24 parallel transistor dies similar or equal to an IRF250 die with each die having a $10 \Omega$ gate resistor. Built in zener diodes provided gate overvoltage protection. Power efficiency was remeasured under the conditions stated earlier and at $5 \mathrm{~kW}$ input and $96 \mathrm{~V}, 50 \mathrm{~A}$ output, was 93.5 percent at $130 \mathrm{~V}$ in., and 93.9 percent at $150 \mathrm{~V}$ in. At $2.5 \mathrm{~kW}$ input and $93 \mathrm{~V}, 25 \mathrm{~A}$ output, power efficiency was 94.6 percent at $130 \mathrm{~V}$ in and 94.4 percent at $150 \mathrm{~V}$ in. 
Mass. - The two heaviest breadboard components were the $1 \mathrm{mH}$ output choke/pulse transformer, which weighed $2.7 \mathrm{kG}$ and the power transformer at $2.9 \mathrm{kG}$. This $5.6 \mathrm{kG}$ mass is the largest fraction of the total component mass and represents only a starting point towards the development of an engineering model. Choke inductance and size can be reduced if operating frequency is increased and output ripple is allowed to increase. Choice of operating frequency, power efficiency and thermal design will impact transformer mass. Furthermore, a flight type transformer design at this power level may require thermal shunts to minimize internal temperatures and extend operating life.

\section{Electronics-Thruster Tests}

Start-up transient and steady state data were taken for the initial design laboratory arcjet and breadboard power electronics. Propellants for these first tests were hydrogen-nitrogen gas mixtures simulating decomposed hydrazine or ammonia. All tests were conducted in the Tank 8 vacuum facility described in reference 16. Diffusion pumps were turned off and the tank pressure was on the order of 1 torr.

\section{Starting and Steady State Tests}

Thruster/power electronics startup current and voltage transients were recorded using an oscilloscope camera and strip chart recorder. Propellant flow was maintained at $2.5 \mathrm{SLM} \mathrm{N} \mathrm{N}_{2}$ and $5.0 \mathrm{SLM} \mathrm{H}_{2}$ simulating decomposed hydrazine, for these tests. The conventional techniques and equipment used are detailed in an earlier paper (ref. 7). Figure 10 shows initial current and voltage transients for current control setpoints of 50, 30, and $10 \mathrm{~A}$ with $135 \mathrm{~V}$ input to the power supply. Thruster transient voltage was measured at the vacuum chamber flange and includes any effects of inductance in the leads to the thruster. Initial current at breakdown was always near $11 \mathrm{~A}$. For all three starts shown, the current increased to about $55 \mathrm{~A}$ in approximately $1 \mathrm{mS}$ and remained there for $5 \mathrm{mS}$ where it was being limited by the pulse by pulse current mode controller preset maximum current limit. Then the integral control loop gradually reduced the current to the selected control reference setpoint.

Evidently this thruster can start at currents much lower than steady state operating current levels. If this characteristic remains after further thruster development, then the inductor/pulse transformer charging circuit need supply only $1 / 20$ of the energy stored in the inductor at the $50 \mathrm{~A}$ operating current.

Typical longer duration voltage, current, and thrust transients are shown in figure 11 for a $50 \mathrm{~A}$ setpoint and $5 \mathrm{~kW}$ operation. There were no significant events between 3 and 32 minutes after startup, so that portion of the recording was omitted from figure 11 . Immediately after ignition, the arc current reaches $50 \mathrm{~A}$ and remains constant. Thruster voltage starts at $93 \mathrm{~V}$ and climbs to $100 \mathrm{~V}$ in about $35 \mathrm{sec}$, finally reaching $103 \mathrm{~V}$ after $34 \mathrm{~min}$. Thrust measured $0.40 \mathrm{~N}$ after $35 \mathrm{sec}$ and $0.42 \mathrm{~N}$ after 34 minutes. For this test, the thruster anode was coated with $\mathrm{CrO}_{2}$ to increase emissivity which 
limited the anode surface maximum temperature to about $1400{ }^{\circ} \mathrm{C}$ measured with an optical pyrometer. Previously, the uncoated anode surface temperature reached about $1870{ }^{\circ} \mathrm{C}$ under these conditions.

During thruster steady state operation at $100 \mathrm{~V}, 50 \mathrm{~A}, 2.5 \mathrm{SLM} \mathrm{N} 2$ and $5.0 \mathrm{SLM} \mathrm{H} \mathrm{H}_{2}$, simulating hydrazine, arc current ripple and thruster voltage ripple were measured at the vacuum tank flange. An arc current ripple of 2 A peak to peak resulted in thruster voltage ripple of about $1 \mathrm{~V}$ peak to peak, $180^{\circ}$ out of phase with arc current ripple are recorded in figure 12 . This same negative resistance characteristic was observed with a $1 \mathrm{~kW}$ system tested earlier (ref. 7).

Maximum steady state thruster power achieved was $6.56 \mathrm{~kW}$ for 3.7 SLM $\mathrm{N}_{2}$ and $11.2 \mathrm{SLM} \mathrm{H}_{2}$, simulated ammonia. Thruster voltage was 131.2 at $50.0 \mathrm{~A}$ arc current with a power supply input voltage of about $150 \mathrm{~V}$. Thrust was $0.645 \mathrm{~N}$.

\section{CONCLUSIONS}

A single stage, $5 \mathrm{~kW}$ arcjet power converter was designed fabricated and evaluated on both resistive and arcjet loads. The circuit was a full bridge pulse width modulated converter that was phase shift regulated to provide constant arc current. The converter design employed MOSFET power switches, current mode control, and included an integral high voltage pulse ignitor. Arcjet start up and operation was verified over a wide range of flow rates with hydrogen/nitrogen mixtures simulating both ammonia and hydrazine.

Resistive load power efficiency at $5 \mathrm{~kW}$ and $50 \mathrm{~A}$ output was 93.5 and 93.9 percent for input voltages of 130 and $150 \mathrm{~V}$ respectively. It is judged that power efficiency can be increased to at least 95 percent by reducing the inductance and copper losses of the output inductor/pulse transformer, by reducing the core and copper losses in the power transformer, and by improving the power circuit to reduce switching losses.

Current mode control limited the initial startup current overshoot to about $55 \mathrm{~A}$. Initial startup current was about $11 \mathrm{~A}$ and this low startup current will permit the pulser design and packaging to remain straightforward, with no need to have semiconductors placed in a high voltage assembiy.

The power stage with power MOSFET's is a high efficiency, low mass approach for circuits requiring low input voltage and high input currents. The major features of this approach are: the transformer leakage inductance energy is well controlled; ON resistance of cascaded switches can be almost the same as for parallel converter single switch-ON resistance; and the intrinsic anti-parallel diodes do not conduct during normal operation if $O N$ resistance is kept low by paralleling enough transistor dies.

\section{APPENDIX-CIRCUIT DETAILS}

The $5 \mathrm{~kW}$ breadboard power electronics breadboard is detailed in three schematic diagrams that represent functionally different, as well as physically separated component assemblies. Figure Al is the bridge power stage and pulser schematic. These power components were located in the main 
chassis (fig. 4) and were cooled by fans. All of the magnetic components for the breadboard are described in table II and are part of this assembly. Figure A2 shows the analog, PWM and pulser controls, which are located on their own printed circuit boards in a shielded assembly, shown with its cover off in figure 4. The PWM to bridge reference and phase shifted bridge drive logic circuit board schematic is shown in figure A3. This circuit board is located in the same shielded box as the control circuit board, figure $A 2$.

The four ideal power switches shown in figure 1 are each made up of four paralleled IRF250 MOSFET's to permit high current, modest power loss switching. Four parallel transistors were used instead of hybrid circuits containing 24 IRF 250 dies to save component cost and procurement time because switch failures were expected to occur during initial development. Eventual use of hybrid MOSFET's was anticipated.

It was experimentally determined that low inductance strip line connections from a low ac impedance voltage source were necessary to prevent excessive ringing because $50 \mathrm{~A}$ current pulses were flowing into the bridge. Conventional circuit layout using short leads was experimentally found to be inadequate. In addition, resistor-capacitor-diode voltage clamps and an R-C snubber were used to protect the power switch drain-source from potential overvoltage transients. The power switch gate-source was protected from overvoltage by back to back zener diodes.

To protect the power MOSFETs from destructive currents due to main transformer, $T_{1}$, core saturation or during faults, a small inductor, $L_{2}$, was placed in series with the $T_{1}$ primary. $L_{2}$ was necessary for this particular design because the current mode control has a delay of one or two $\mu s$ and the saturation characteristic of $T_{1}$ exhibits a high rate of current rise. Switching transistor current sensing was important for pulse by pulse current control and high noise levels complicated this task. Instead of using resources to develop a shielded, high fidelity current transformer, the breadboard incorporated a commercial current transformer, $T_{4}$, with its distributed $50 \Omega$ burden resistance, together with a signal transformer, $T_{5}$, used to isolate the current transformer return.

The pulser used the same low voltage winding inductor charging scheme detailed elsewhere (ref. 8), except that three IRF460 transistors rated at $500 \mathrm{~V}$ were used instead of two $400 \mathrm{~V}$ IRF 350 devices. The IRF460's ON time was adjusted to provide about $120 \mathrm{~A}$ peak charging current to the $L_{1}$ averaging inductor/pulse transformer primary.

The control circuits in figure $A 2$ are similar to those used in the $1 \mathrm{~kW}$ power supply and are detailed in references 7 and 8 . A UC1846 pulse width modulation current current mode control integrated circuit forms the basis for implementing the control scheme function shown in figure 2 . However, this design used an external error amplifier instead of the UCl846 error amplifier to ease insertion of ramp compensation and to provide more flexibility should future control loop changes be desired. In addition, this design incorporated the UCl846 shutdown-recycle function to provide protection in the unlikely event of short circuits, where no energy is delivered to the load and current buildup can occur as described in other work (ref. 13). At this writing, the shutdown-recycle function was not yet tested under a short circuit at $50 \mathrm{~A}$, so the component values may need further adjustment. The signal conversion function of PWM to reference and phase shifted bridge drive is shown in 
function of PWM to reference and phase shifted bridge drive is shown in figure 2 and the schematic in figure $A 3$ details the implementation of:

$$
\phi_{S}=\bar{\phi}_{R} \cdot(A+B)+\phi_{R} \cdot \overline{(A+B)}
$$

Two AND gates identified by output pins 10 and 11 of integrated circuit 4061 were connected to provide a small delay needed to correct a potential race problem. Bridge drive was provided by $N$ and $P$ channel power MOSFET's ac coupled to drive transformers $T_{2}$ and $T_{3}$.

\section{REFERENCES}

1. Stone, J.R., Byers, D.C., and King, D.Q., "The NASA Electric Propulsion Program," IEPC-88-002, Oct. 1988. (NASA TM-101324).

2. Deininger, W.D., Pivirotto, and Brophy, J.R., "The Design and Operating Characteristics of an Advanced 30-kW Ammonia Arcjet Engine," AIAA 87-1082, May 1987.

3. Cassady, R.J., Britt, E.J., and Meya, R.D., "Performance Testing of A Lightweight 30-kW Arcjet Power Conditioning Unit," AIAA 87-1085, May 1987.

4. Knowles, S.C. and Yano, S.E., "Engineering Model Low Power Arcjet System Development," 1989 JANNAF Propulsion Meeting, Cleveland, Ohio, May 1989.

5. Lovell, R.R. and O' Malley, T.A., "Station Keeping of High Power Communication Satellites," NASA TMX-2136, 1970.

6. Patterson, M.J. and Curran, F.M., "Electric Propulsion Options for 10-kW Class Earth-Space Missions," 1989 JANNAF Propulsion Meeting, Cleveland, Ohio, May 1989.

7. Gruber, R.P., "Power Electronics for a l-Kilowatt Arcjet Thruster," AIAA 86-1507, June 1986.

8. Sarmiento, C.J., and Gruber, R.P., "Low Power Arcjet Thruster Pulse Ignition," AIAA Paper 87-1951, Juily 1987. (NASA TM-100123)

9. Curran, F.M., and Haag, T.W., "An Extended Life Performance Test of a Low-Power Arcjet," AIAA Paper 88-3106, July 1988. (NASA TM-100942)

10. Herron, B.G., and Hopper, D.J., "The 30-cm Ion Thruster Power Processor," Hughes Research Laboratories, Malibu, CA, 90265, Jan. 1978, NASA CR-135401.

11. Goldfarb, R., "A New Non-Dissipative Load-Line Shaping Technique Eliminates Switching Stress in Bridge Converters," Proceedings of Powercon 8, Power Concepts, Inc., 1981, pp. D-4.1 to D-4.6.

12. Ernsberger, G.W., "An Experimental Model of a 2 kW, 2500 Volt Power Converter for Ion Thrustors Using Silicon Transistors in a Pulse-Width-Modulated Bridge Inverter, "WAED65-12E, Westinghouse Electric Corporation, Box 989, Lima, OH Mar. 1965, NASA CR-54217. 
13. Ahrens, A.F., and Cardwe11, G.I., "Arc Discharage Supply Component Protection Circuitry," IEEE Power Electronics Specialists Conference Record, 1976, IEEE, New York, pp. 326-333.

14. Deisch, C.W., "Simple Switch Control Method Changes Power Converter into a Current Source," PESC ' 78 Record, L. Ogborn, ed., IEEE, Piscataway, NJ, 1978, pp. 300-306.

15. Holland, B., "Modeling Analysis and Compensation of the Current-Mode Converter," Proceedings of Powercon 11, R.I. Birdsall, ed., Power Concepts, Inc., 1984, pp. I-2 to I-2.6.

16. Nakanishi, S., "Experimental Performance of a $1 \mathrm{~kW}$ Arc jet Thruster," AIAA Paper 85-2033, Oct. 1985. 
TABLE I. - POWER SUPPLY STATIC LOAD CHARACTERISTICS

\begin{tabular}{|c|c|c|c|c|c|c|c|}
\hline \multicolumn{2}{|c|}{$\begin{array}{l}50 \mathrm{~A} \text { Setpoint } \\
130 \mathrm{~V} \text { Input }\end{array}$} & \multicolumn{2}{|c|}{$\begin{array}{l}50 \text { A Setpoint } \\
150 \mathrm{~V} \text { Input }\end{array}$} & \multicolumn{2}{|c|}{$\begin{array}{l}10 \mathrm{~A} \text { Setpoint } \\
130 \mathrm{~V} \text { Input }\end{array}$} & \multicolumn{2}{|c|}{$\begin{array}{l}10 \mathrm{~A} \text { Setpoint } \\
150 \mathrm{~V} \text { Input }\end{array}$} \\
\hline $\begin{array}{c}\text { Voltage, } \\
\mathrm{V}\end{array}$ & $\begin{array}{c}\text { Current, } \\
\text { A }\end{array}$ & $\begin{array}{c}\text { Voltage, } \\
\mathrm{V}\end{array}$ & $\begin{array}{c}\text { Current, } \\
\text { A }\end{array}$ & $\begin{array}{c}\text { Voltage, } \\
\mathrm{V}\end{array}$ & $\begin{array}{c}\text { Current, } \\
\text { A }\end{array}$ & $\begin{array}{c}\text { Voltage, } \\
\text { A }\end{array}$ & $\begin{array}{c}\text { Current, } \\
\text { A }\end{array}$ \\
\hline $\begin{array}{c}184.8 \\
130.1 \\
129.3 \\
128.3 \\
127.6 \\
127.0 \\
126.3 \\
125.7 \\
124.9 \\
122.4 \\
120.1 \\
118.0 \\
96.2 \\
87.6 \\
80.6 \\
72.8 \\
61.0 \\
46.9 \\
20.4 \\
1.35\end{array}$ & $\begin{array}{r}0.0 \\
1.1 \\
2.2 \\
5.3 \\
7.5 \\
9.6 \\
11.7 \\
13.8 \\
16.7 \\
24.7 \\
32.4 \\
39.8 \\
50.1 \\
50.1 \\
50.1 \\
50.2 \\
50.2 \\
50.1 \\
50.2 \\
50.3\end{array}$ & $\begin{array}{l}206 \\
150.1 \\
148.9 \\
147.7 \\
146.9 \\
146.2 \\
145.5 \\
144.8 \\
143.8 \\
141.1 \\
138.6 \\
136.2 \\
95.8 \\
87.3 \\
80.3 \\
72.5 \\
60.7 \\
46.8 \\
20.3 \\
1.36\end{array}$ & $\begin{array}{l}0 \\
1.3 \\
2.5 \\
6.1 \\
8.6 \\
11.1 \\
13.5 \\
15.9 \\
19.2 \\
28.5 \\
37.6 \\
46.2 \\
50.1 \\
50.1 \\
50.1 \\
50.1 \\
50.1 \\
50.1 \\
50.1 \\
50.1\end{array}$ & $\begin{array}{c}184.5 \\
130.6 \\
129.8 \\
128.7 \\
128.0 \\
127.3 \\
109.6 \\
91.2 \\
75.0 \\
49.8 \\
37.3 \\
29.9 \\
19.2 \\
17.7 \\
16.3 \\
14.7 \\
12.27 \\
9.47 \\
4.18\end{array}$ & $\begin{array}{r}0.0 \\
1.2 \\
2.3 \\
5.3 \\
7.5 \\
9.6 \\
10.1 \\
10.0 \\
10.0 \\
10.0 \\
10.1 \\
10.1 \\
10.1 \\
10.1 \\
10.1 \\
10.1 \\
10.1 \\
10.1 \\
10.2\end{array}$ & $\begin{array}{l}205 \\
150.0 \\
149.1 \\
148.0 \\
147.2 \\
131.3 \\
106.7 \\
90.3 \\
74.4 \\
49.3 \\
37.0 \\
29.6 \\
19.0 \\
17.4 \\
16.0 \\
14.4 \\
12.03 \\
9.26 \\
4.06\end{array}$ & $\begin{array}{r}0.0 \\
1.3 \\
2.6 \\
6.1 \\
8.6 \\
10.0 \\
9.9 \\
9.9 \\
9.9 \\
9.9 \\
10.0 \\
10.0 \\
10.0 \\
10.0 \\
10.0 \\
9.9 \\
9.9 \\
9.9 \\
9.9\end{array}$ \\
\hline
\end{tabular}

TABLE II. - MAGNETIC COMPONENTS

\begin{tabular}{|c|c|c|c|}
\hline Component & Function & Core & Windings \\
\hline$T_{1}$ & $\begin{array}{l}\text { Power } \\
\text { transformer }\end{array}$ & $\begin{array}{l}\text { "C" core, Arnold } \mathrm{Cl} 202 \\
\text { PIAA with } 0.46 \mathrm{~mm} \text { gap } / 1 \mathrm{eg}\end{array}$ & $\begin{array}{l}\text { Primary: Two } 21 \mathrm{~T} \text { No. } 9 \text { AWG square HML } \\
\text { first layer each leg; parallel connected } \\
\text { Secondary: Four } 22 \mathrm{~T} \text { No. } 10 \text { AWG square, } \\
\text { HML Two layers, two windings bifilar } \\
\text { on each leg }\end{array}$ \\
\hline$T_{2}, T_{3}$ & $\begin{array}{l}\text { Drive } \\
\text { transformer }\end{array}$ & $\begin{array}{l}\text { Ferrite Toroid } \\
19 \mathrm{~mm} \text { i.d., } \\
37 \mathrm{~mm} \text { o.d.: } \\
12 \mathrm{~mm} \text { hight } \\
\text { unknown material }\end{array}$ & $\begin{array}{l}\text { Approximately } 40 \text { T No. } 26 \text { AWG, U1-1422 } \\
\text { Trifilar, one layer about } 330^{\circ}\end{array}$ \\
\hline$T_{4}$, & $\begin{array}{l}\text { Current } \\
\text { transformer } \\
\text { with burden } \\
\text { resistance }\end{array}$ & $\begin{array}{l}\text { Model } 410,0.1 \mathrm{~V} / \mathrm{A}, 50 \Omega \\
\text { source impedance }\end{array}$ & \\
\hline$T_{5}$ & $\begin{array}{l}\text { Signal } \\
\text { transformer }\end{array}$ & $1: 1$ turns ratio & \\
\hline$L_{1}$ & $\begin{array}{l}\text { Output inductor/ } \\
\text { pulse transformer }\end{array}$ & $\begin{array}{l}\text { "C" core AM-57 with } \\
3.8 \mathrm{~mm} \text { gap/leg }\end{array}$ & $\begin{array}{l}\text { Main winding: } 78 \mathrm{~T} \text { No.8 AWG square } \\
\text { HML } 2 \text { layers each leg } \\
\text { Pulser winding: } 8 \mathrm{~T} \text { copper braid, } \\
4 \mathrm{~T} \text { each leg }\end{array}$ \\
\hline $\mathrm{L}_{2}$ & $\begin{array}{l}\text { Current limiting } \\
\text { inductor }\end{array}$ & 55252 Mag. Inc. & 4 turns copper briad \\
\hline
\end{tabular}



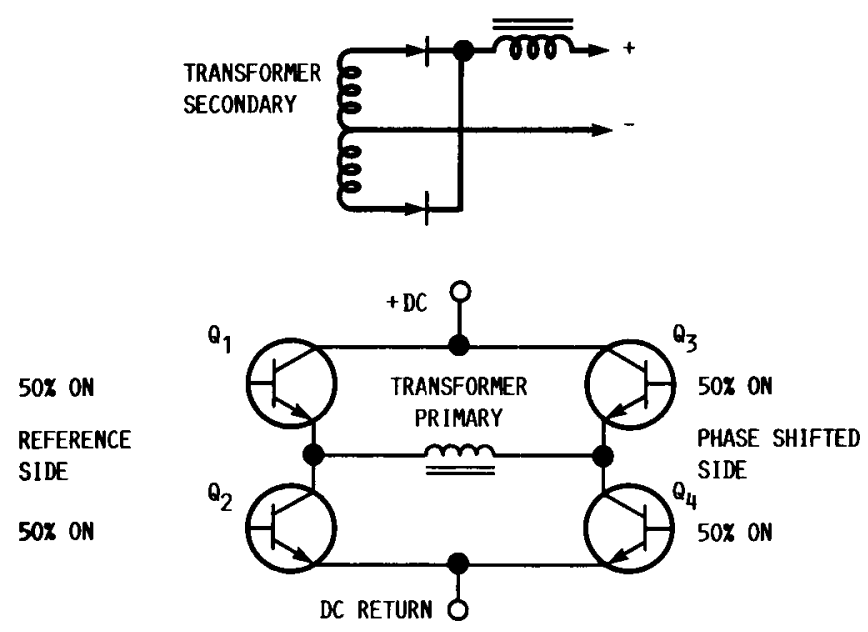

(a) FULL BRIDGE CONVERTER.

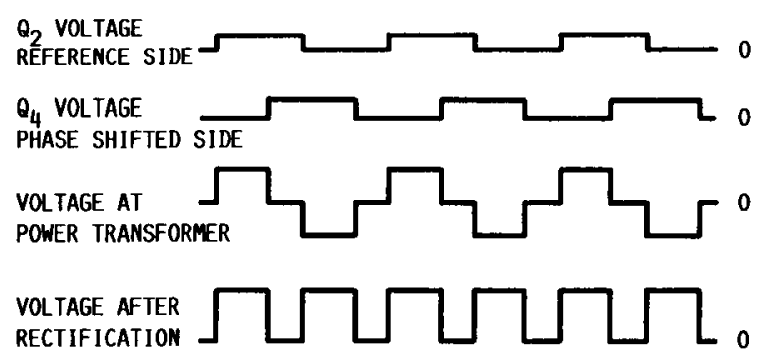

(b) VOLTAGE WAVEFORMS.

FIGURE 1. - FULL BRIDGE CONVERTER WITH VOLTAGE WAVEFORMS (REF. 13). 


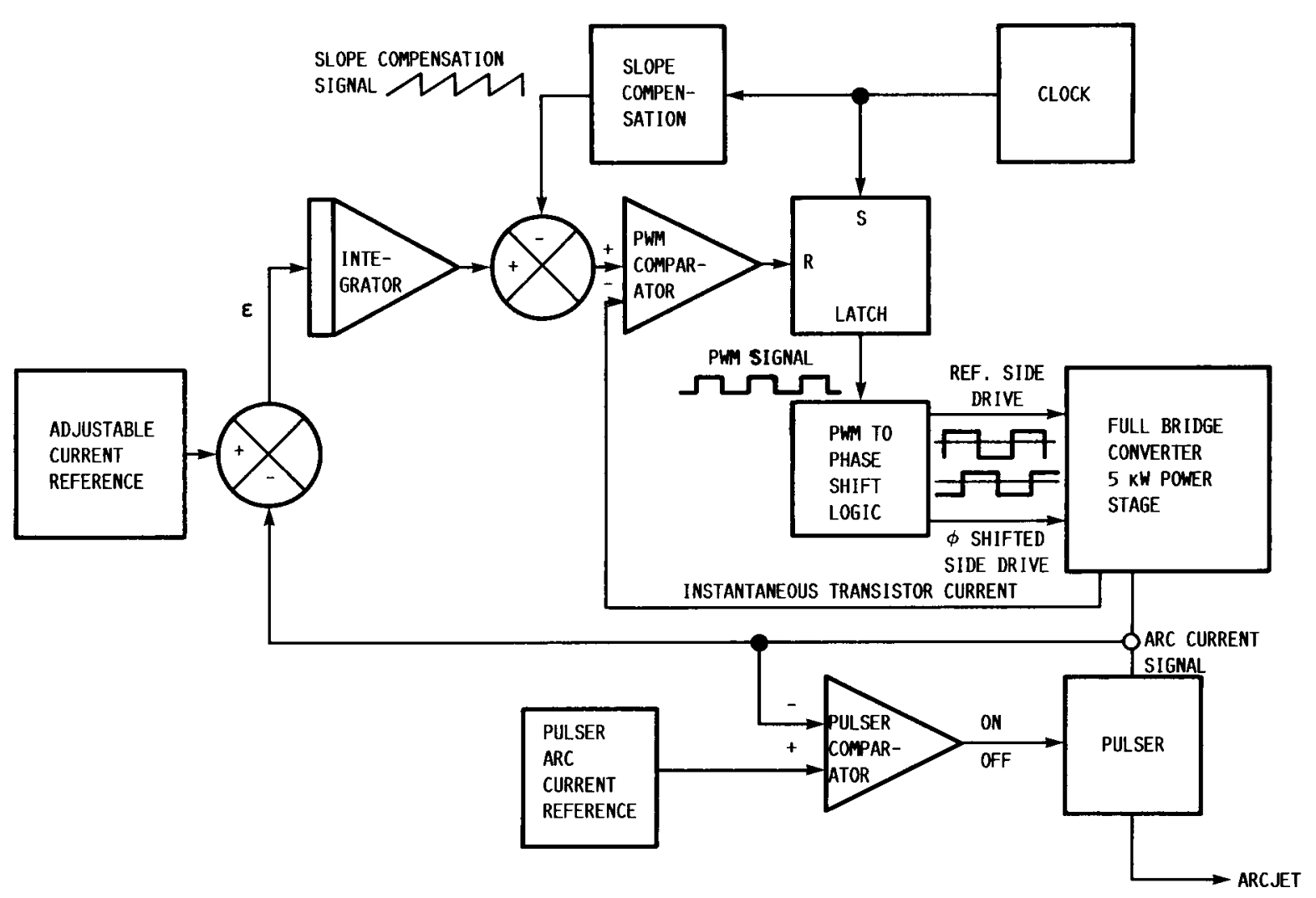

FIGURE 2. - POWER ELECTRONICS FUNCTIONAL DIAGRAM.

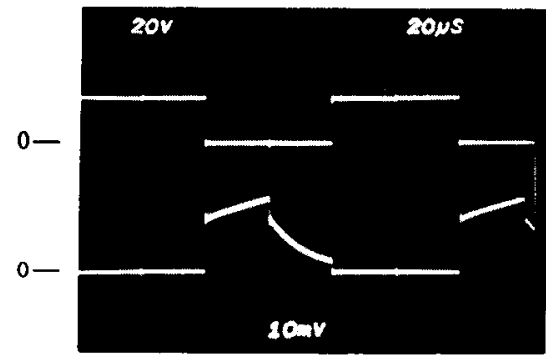

$\theta_{1}$

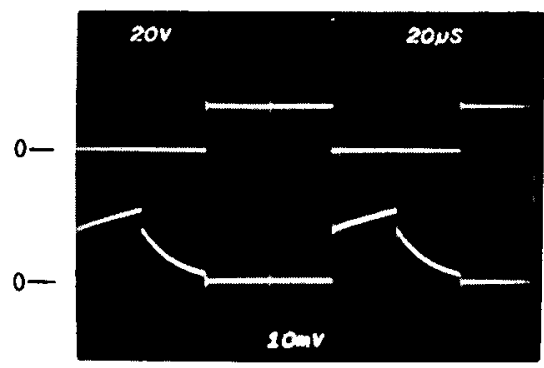

$\mathrm{O}_{2}$

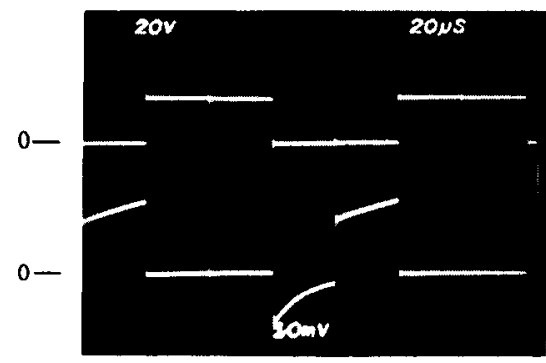

$\theta_{3}$

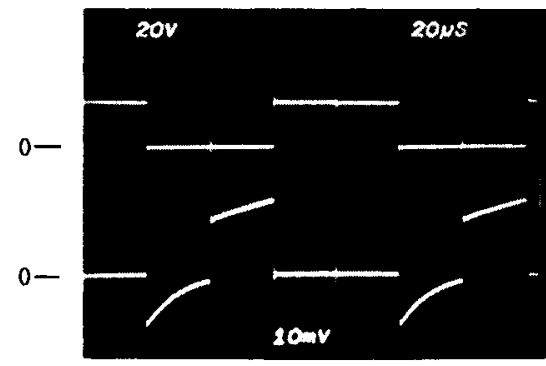

$Q_{4}$

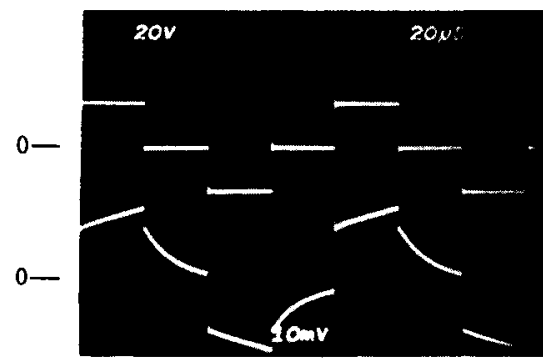

TRANSFORMER PRIMARY

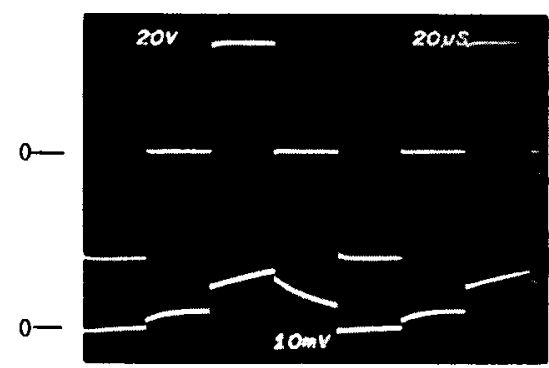

TRANSFORMER 1/2 SECONDARY

FIGURE 3. - SYNCHRONIZED WAVEFORMS FROM 30 W MODEL CONVERTER. $Q_{1}$ THROUGH $Q_{4}$ TOP TRACES ARE DRAIN TO SOURCE VOLTAGES (20 V/ DIV): BOTTOM TRACES ARE DRAIN CURRENTS ( 1 A/DIV). TRANSFORMER PRIMARY AND TRAMSFORMER $1 / 2$ SECONDARY TOP TRACE IS VOLTAGE (20 V/DIV) AND BOTTOM TRACE IS CURRENT (1 A DIV). 


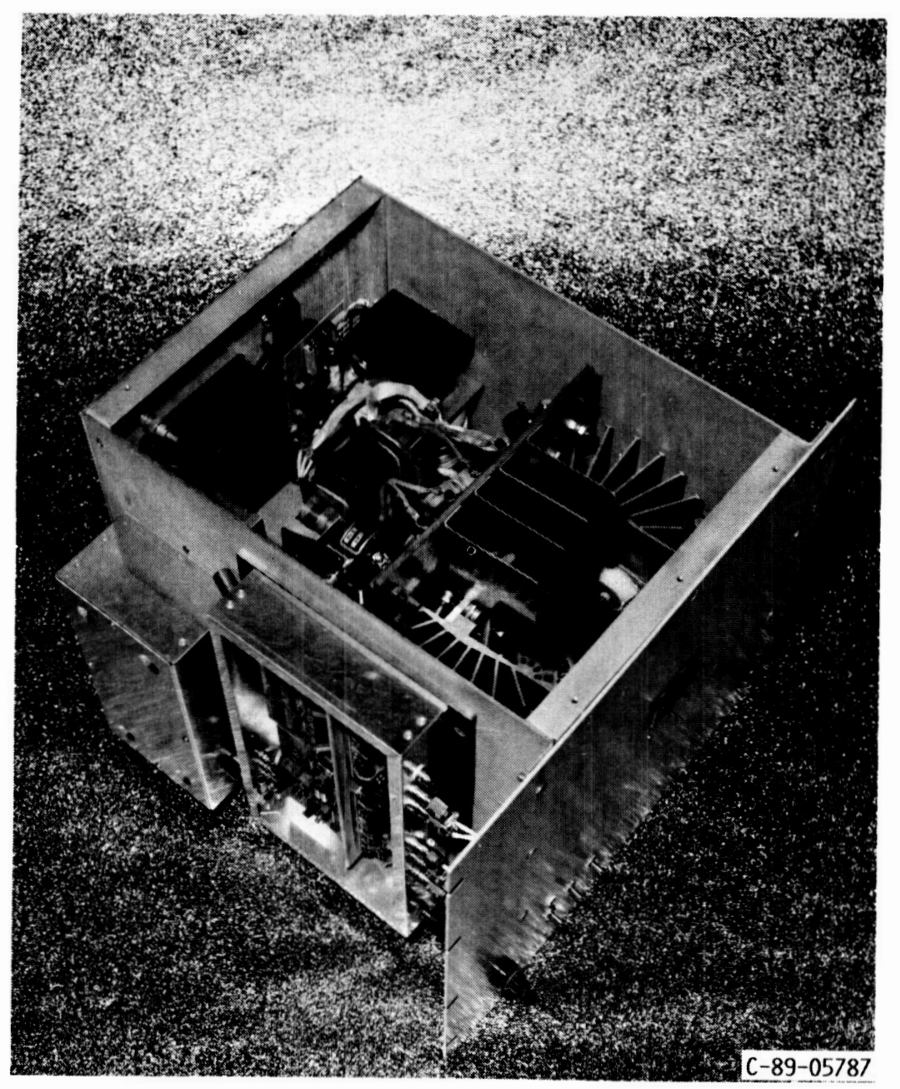

FIGURE 4. - POWER ELECTRONICS $5 \mathrm{~kW}$ BREADBOARD.

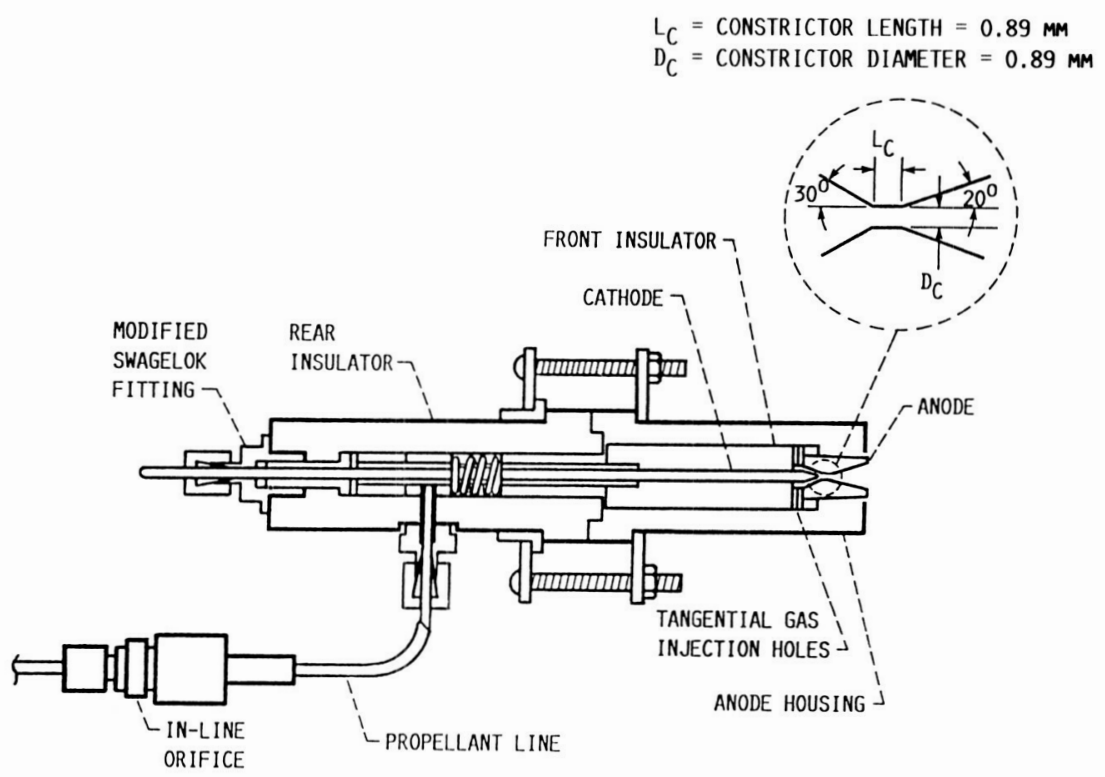

FIGURE 5. - CUTAWAY VIEW OF ARCJET THRUSTER WITH ANODE DIMENSIONS DESCRIBED. 


\section{ORIGINAL PAGE}

BLACK AND WHITE PIIOTOGRAPH

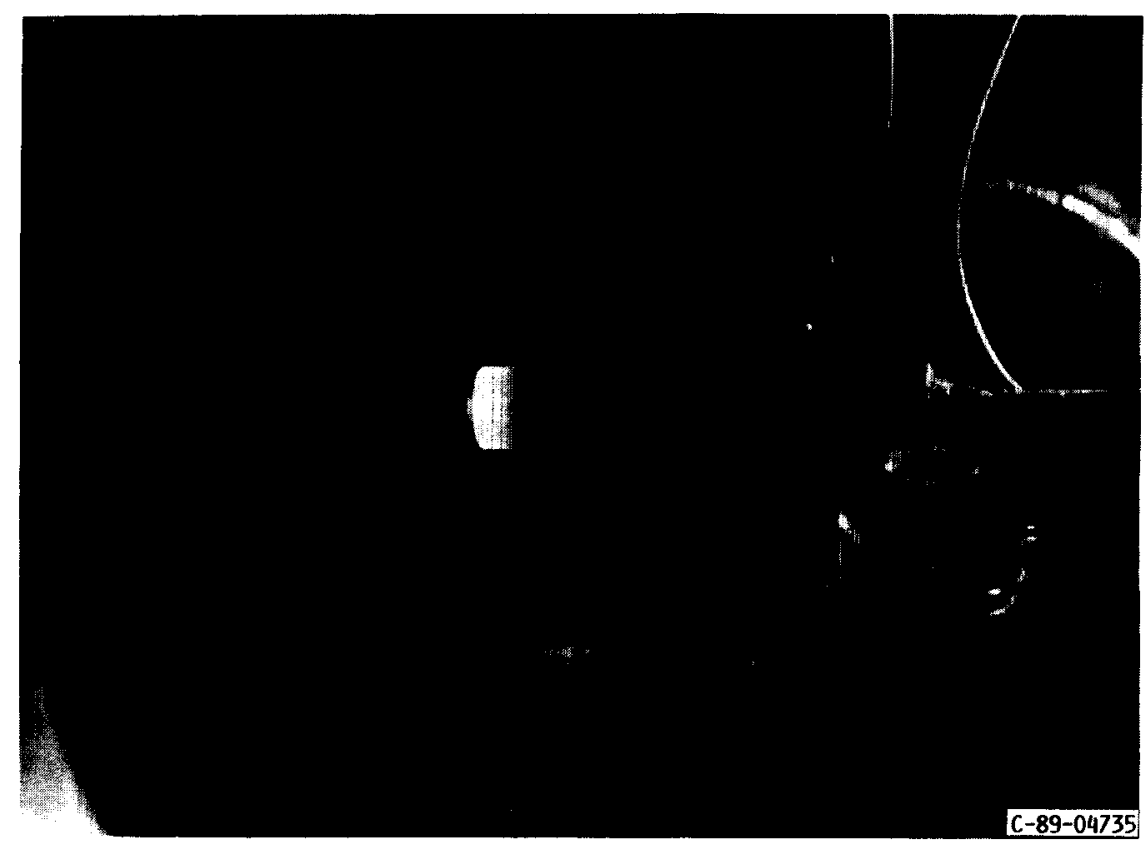

FIGURE 6. - LABORATORY $5 \mathrm{~kW}$ ARCJET IN OPERATION ON THRUST STAND.

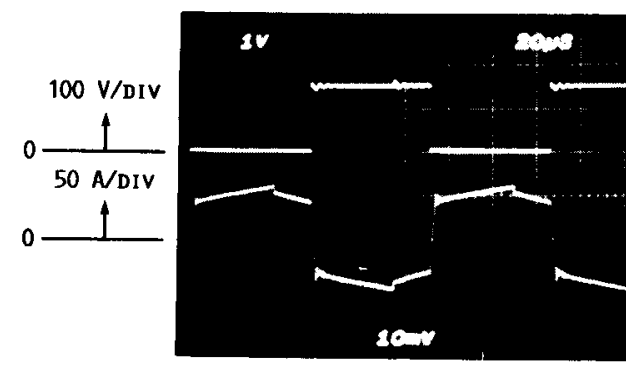

REFERENCE SIDE

$\left(\mathrm{Q}_{2}\right)$ SWITCH

VOLTAGE

\section{TRANSFORMER}

PRIMARY

CURRENT
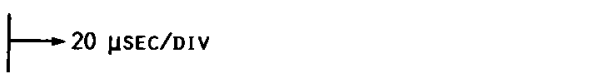

$-89-04735$

CuRENT
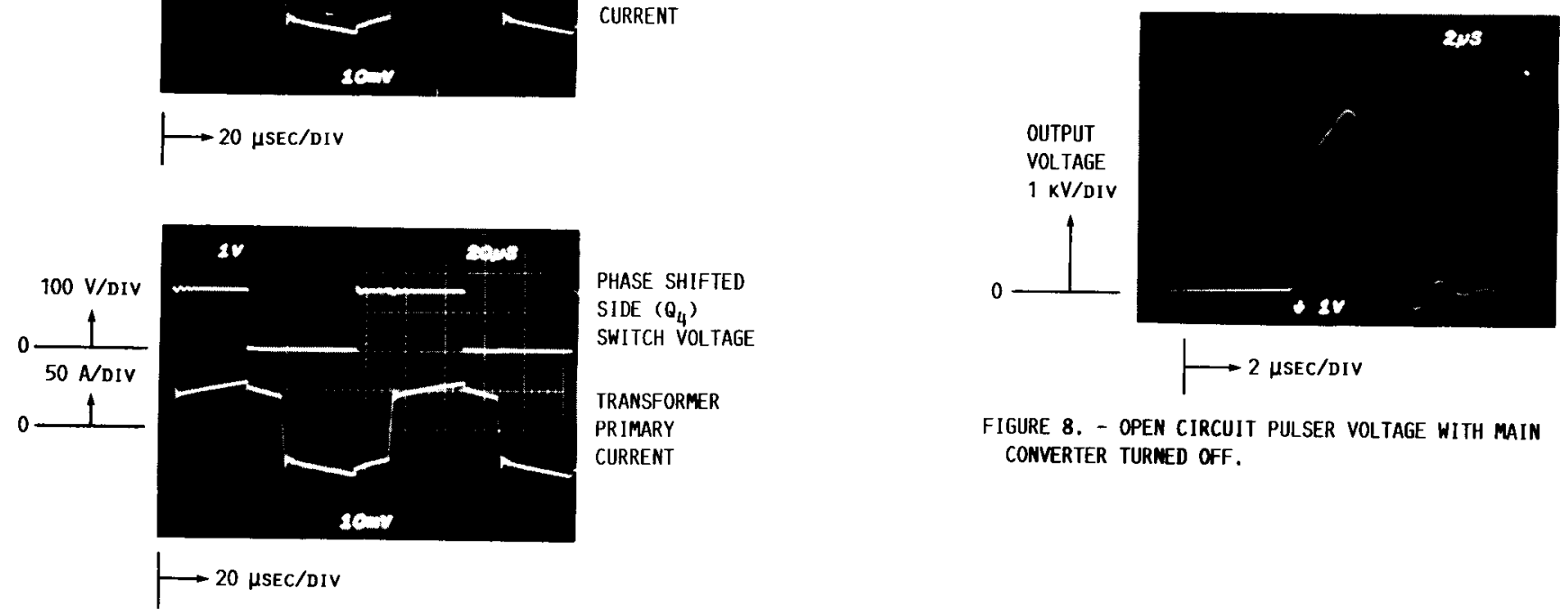

FIGURE 7. - MOSFET VOLTAGE AND TRANSFORMER PRIMARY CURRENT FOR $150 \mathrm{~V}$ INPUT, $96 \mathrm{~V}, 50 \mathrm{~A}$ OUTPUT. 


\section{ORIGINAL PAGE \\ BLACK AND WHITE PHOTOGRAPH}
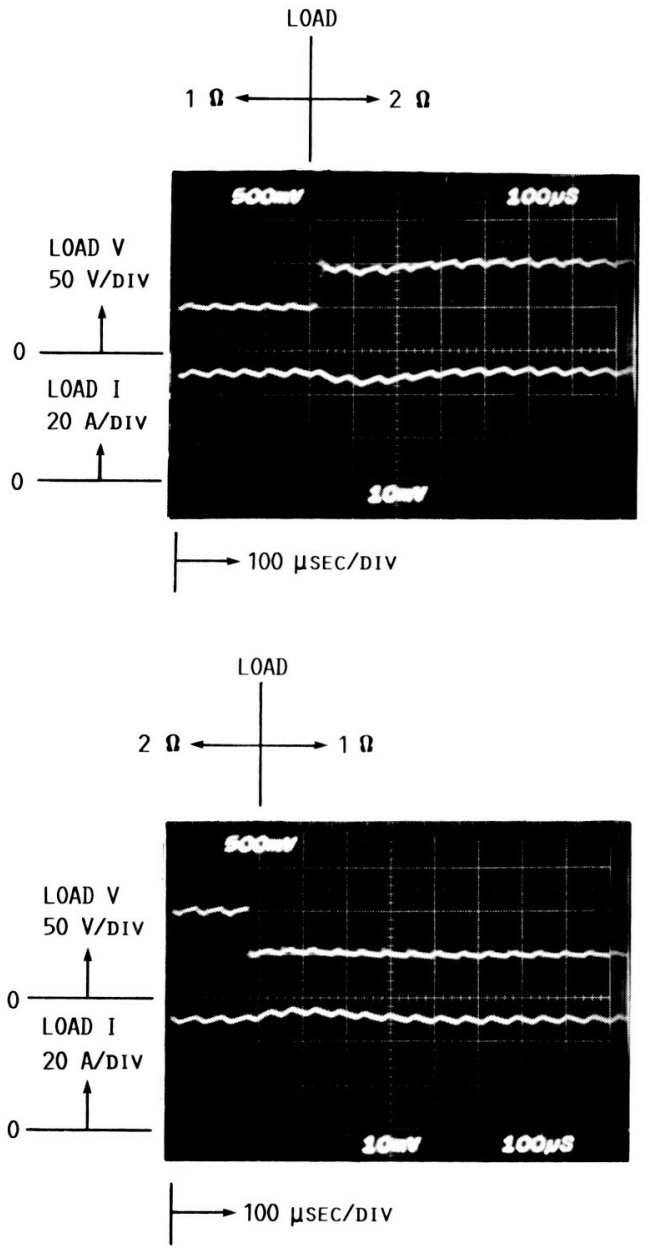

FIGURE 9. - POWER SUPPLY TRANSIENT REPSONSE TO STEP LOAD CHANGES FROM 1 TO $2 \mathbf{\Omega}$ AND FROM 2 TO $1 \mathbf{\Omega}$ AT $150 \mathrm{~V}$ INPUT.

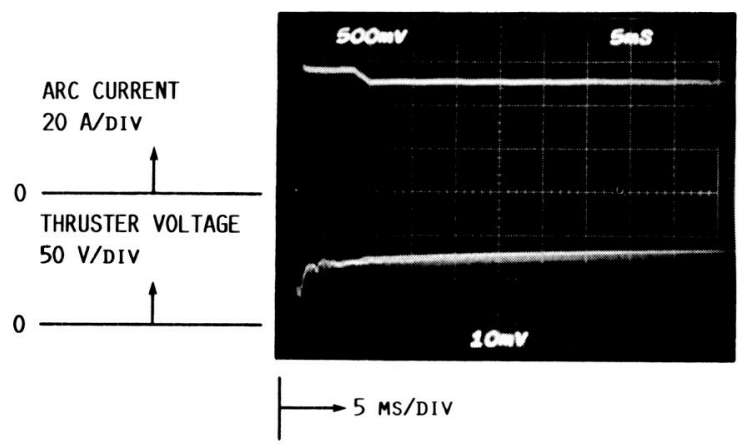

(a) 50 A SETPOINT.

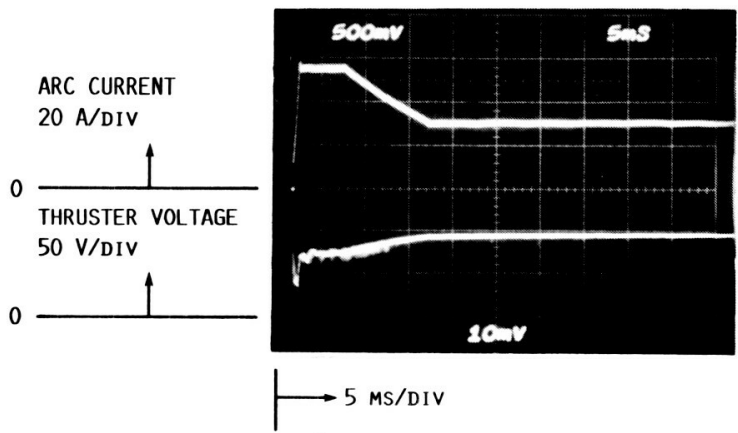

(b) $30 \mathrm{~A}$ SETPOINT.
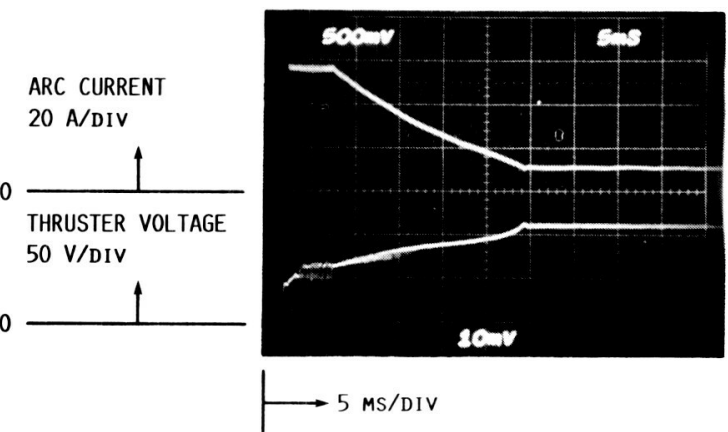

(c) 10 A SETPOINT.

FIGURE 10. - THRUSTER STARTUP CURRENT AND VOLTAGE AT THE VACUUM TANK FLANGE FOR (a) $50 \mathrm{~A}$, (b) $30 \mathrm{~A}$, AND (c) $10 \mathrm{~A}$ SETPOINTS UNDER CONDITIONS OF 2.5 SLM N $\mathrm{N}_{2}, 5.0 \mathrm{SLM} \mathrm{H} \mathrm{H}_{2}$ AND $135 \mathrm{~V}$ INPUT TO POWER SUPPLY. 


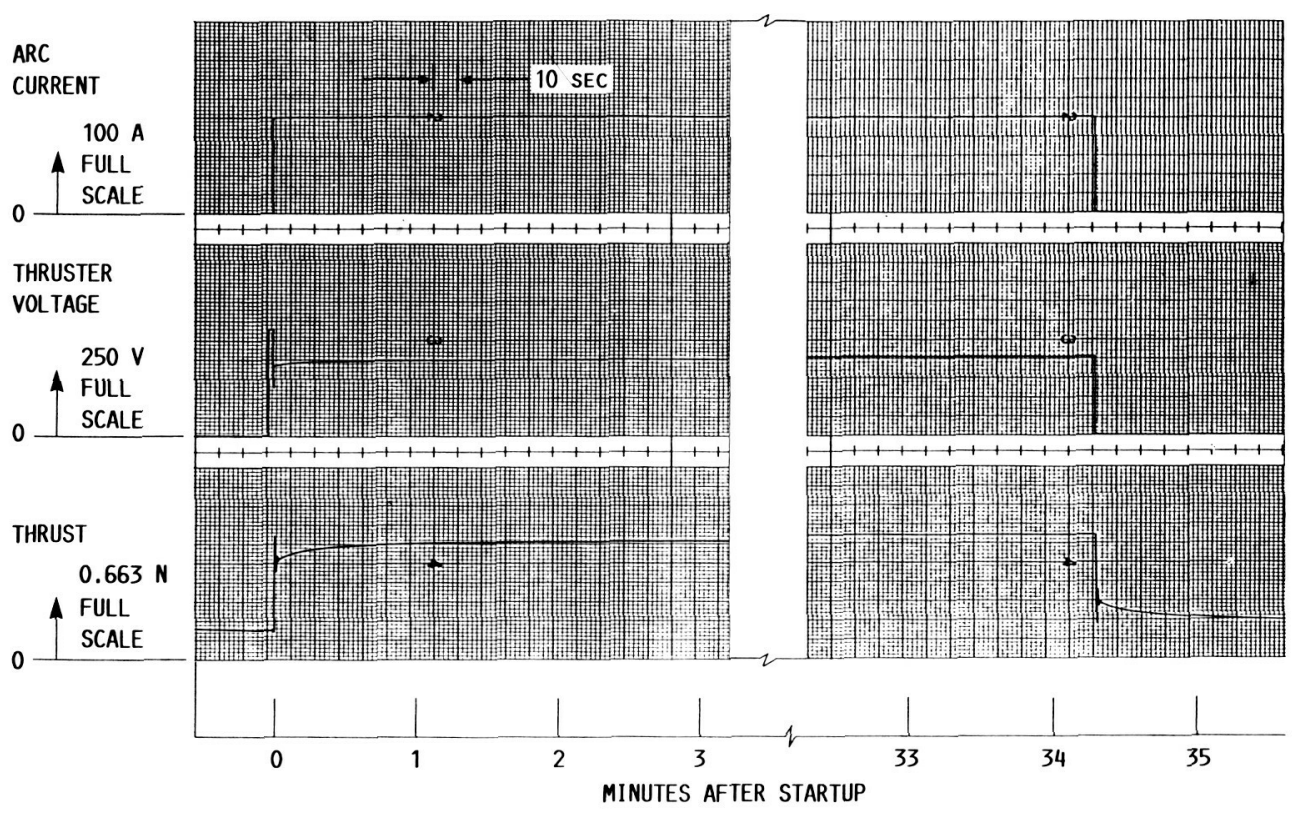

FIGURE 11. - TYPICAL THRUSTER STARTUP AND STEADY STATE CURRENT, VOLTAGE, AND THRUST UNDER CONDITIONS OF $2.5 \mathrm{SLM} \mathrm{N}_{2}$ AND $5.0 \mathrm{SLM} \mathrm{H}_{2}$.

ARC CURRENT

RIPPLE

5 A/DIV

ARC VOLTAGE

RIPPLE

2 V/DIV

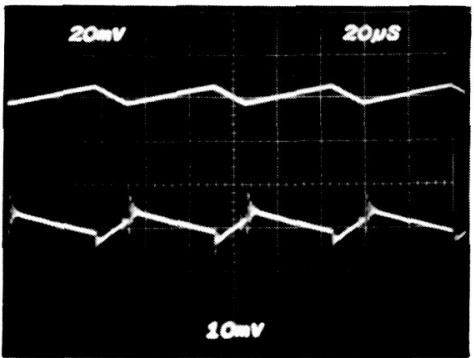

FIGURE 12. - THRUSTER STEADY STATE ARC CURRENT AND VOLTAGE AT THE VACUUM TANK FLANGE RIPPLE UNDER CONDITIONS OF $2.5 \mathrm{SLM} \mathrm{N}_{2}, 5.0 \mathrm{SLM} \mathrm{H}_{2}, 150 \mathrm{~V}$ INPUT, AND $100 \mathrm{~V}, 50 \mathrm{~A}$ OUTPUT. 


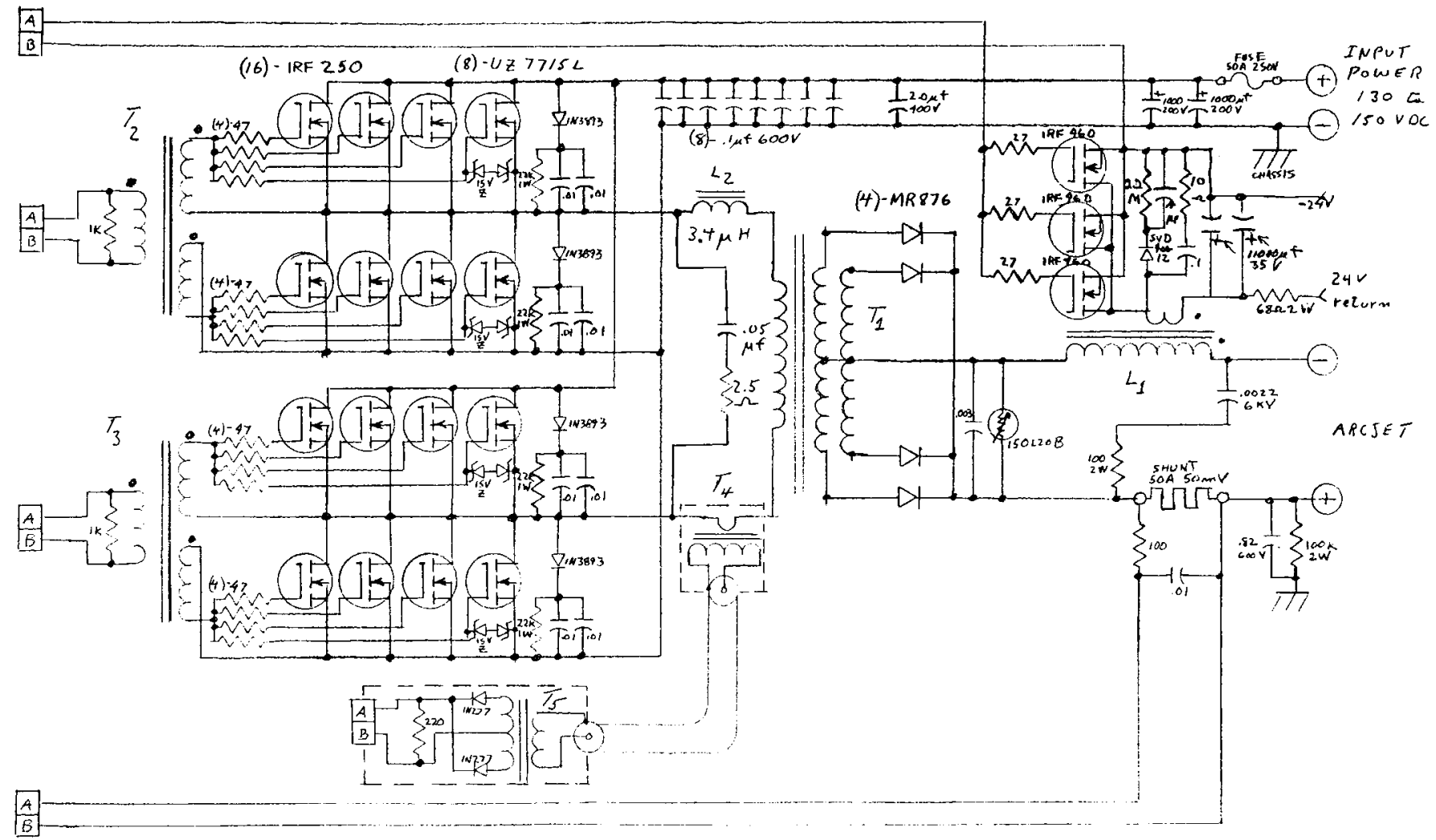

FIGURE A1. - 5 KW POWER STAGE AND PULSER SCHEMATIC. 


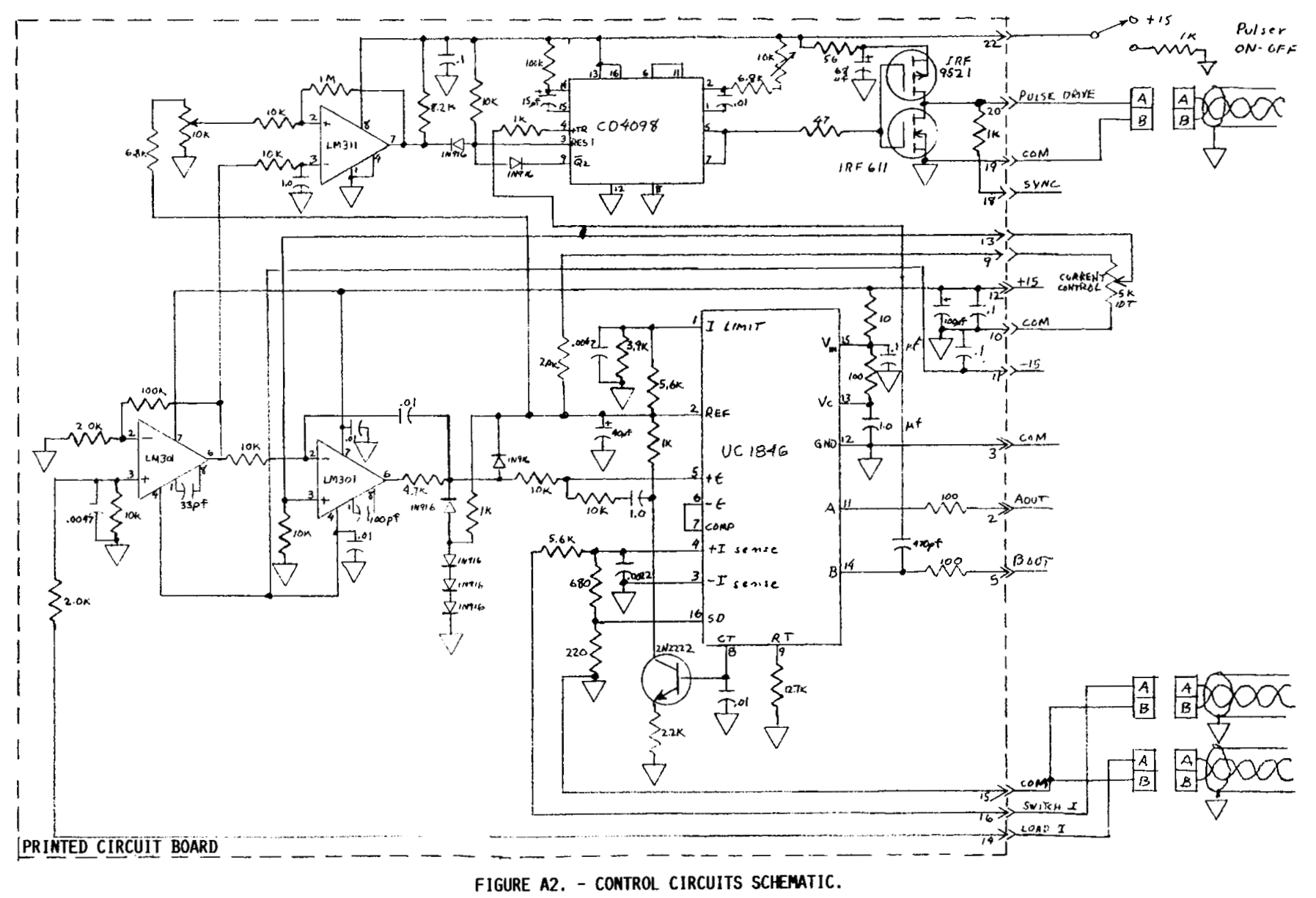




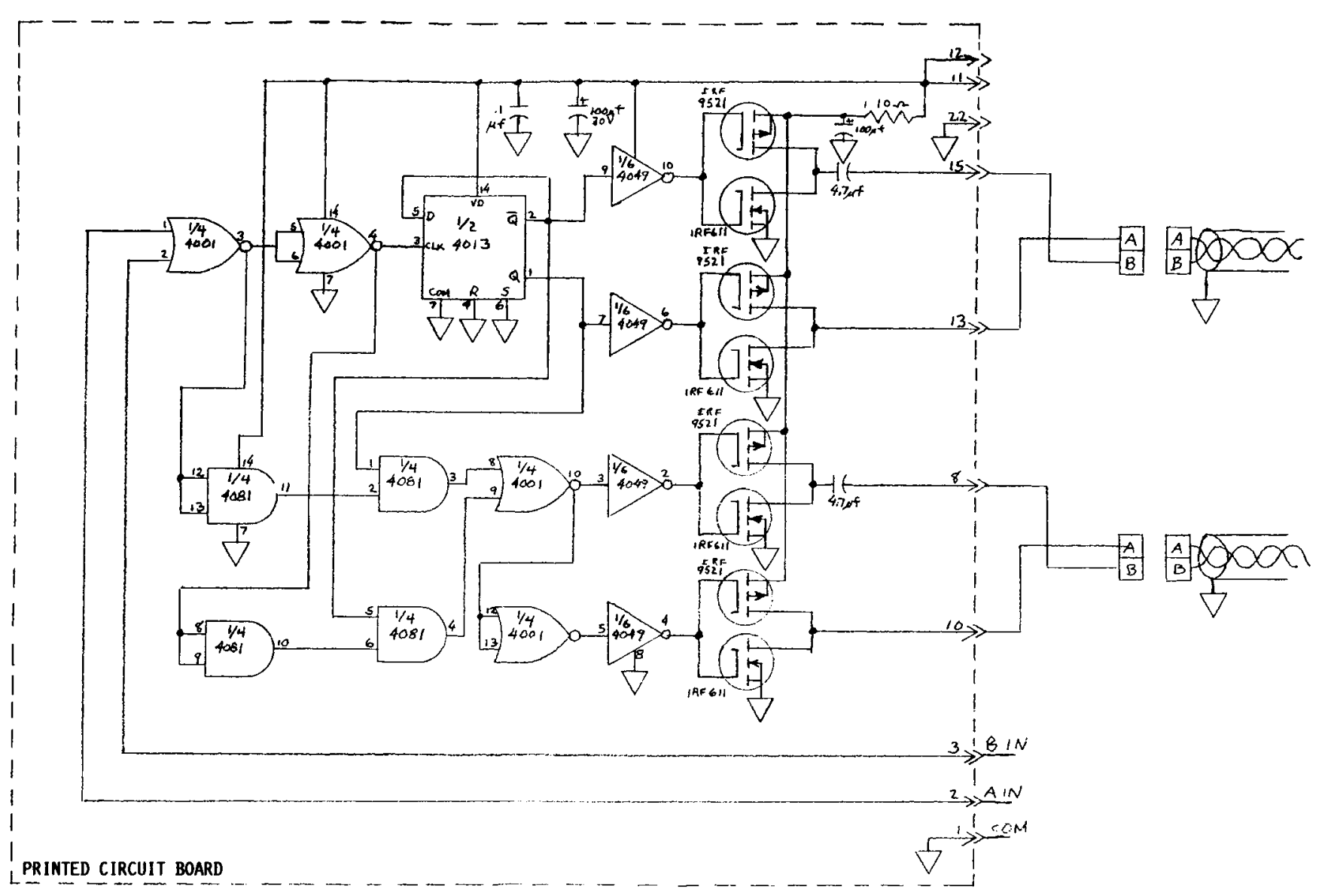

FIGURE A3. - LOGIC AND DRIVE CIRCUIT SCHEMATIC. 


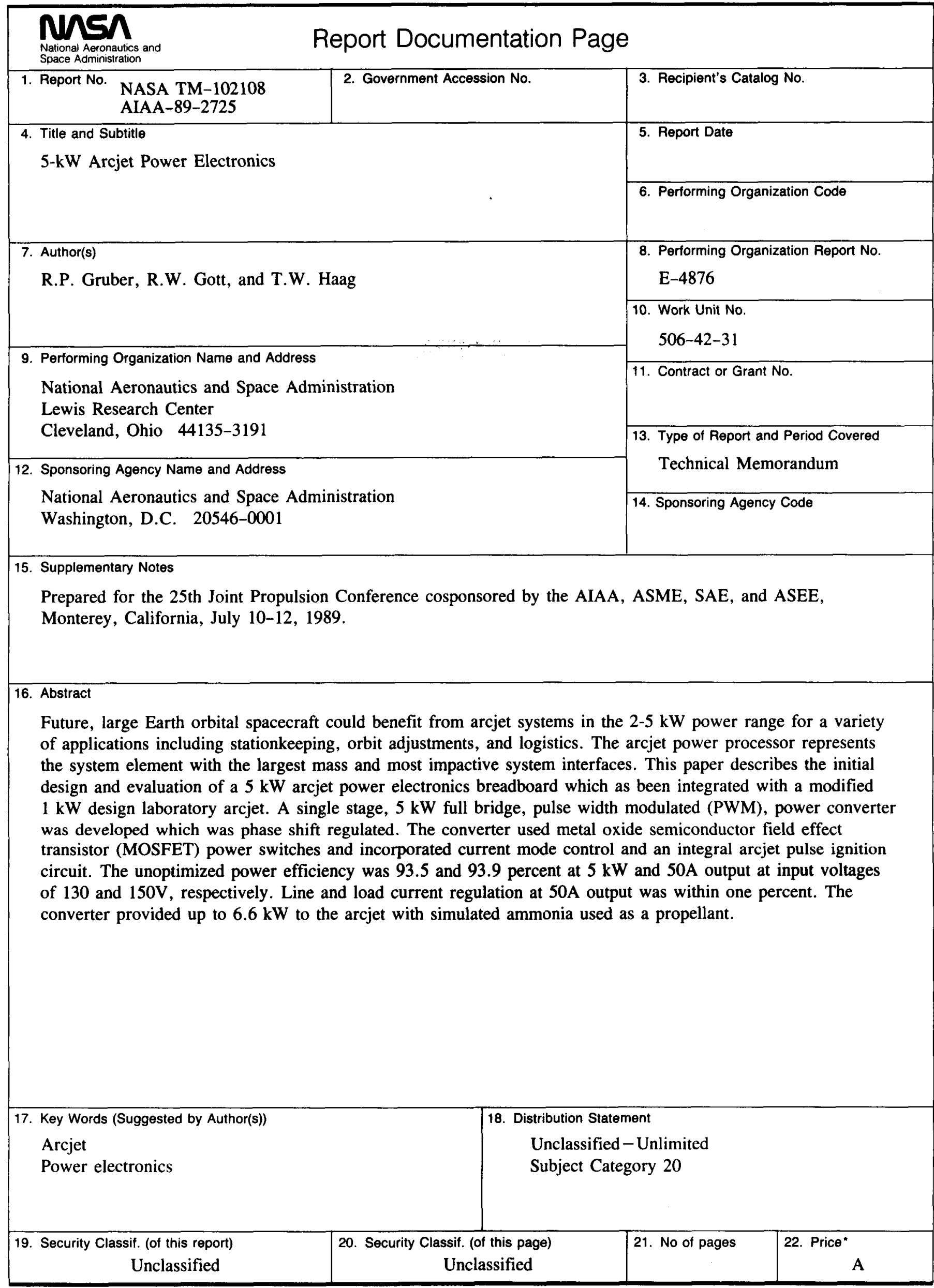

